\title{
The Effect of Hydrogen Addition on the Combustion Characteristics of RP-3 Kerosene/Air Premixed Flames
}

\author{
Wen Zeng *, Jing Liu, Yu Liu, Baodong Chen and Aiguo Liu \\ Liaoning Key Lab of Advanced Test Technology for Aerospace Propulsion System, \\ Shenyang Aerospace University, Shenyang 110136, China; liu_jingnew@126.com (J.L.); \\ liu_yunew@126.com (Y.L.); chenbaodongnew@126.com (B.C.); agliu@sau.edu.cn (A.L.) \\ * Correspondence: zengwennew@126.com; Tel.: +86-248-972-3722; Fax: +86-248-972-3720
}

Received: 19 April 2017; Accepted: 18 July 2017; Published: 30 July 2017

\begin{abstract}
Experimental studies have been performed to investigate the effects of hydrogen addition on the combustion characteristics of Chinese No.3 jet fuel (RP-3 kerosene/air premixed flames. Experiments were carried out in a constant volume chamber and the influences of the initial temperatures of 390 and $420 \mathrm{~K}$, initial pressures of 0.1 and $0.3 \mathrm{MPa}$, equivalence ratios of 0.6-1.6 and hydrogen additions of $0.0-0.5$ on the laminar burning velocities, and Markstein numbers of Hydrogen $\left(\mathrm{H}_{2}\right) / \mathrm{RP}-3 /$ air mixtures were investigated. The results show that the flame front surfaces of RP-3/air mixtures remain smooth throughout the entire flame propagation process at a temperature of $390 \mathrm{~K}$, pressure of $0.3 \mathrm{MPa}$, equivalence ratio of 1.3 and without hydrogen addition, but when the hydrogen addition increases from 0.0 to 0.5 under the same conditions, flaws and protuberances occur at the flame surfaces. It was also found that with the increase of the equivalence ratio from 0.9 to 1.5 , the laminar burning velocities of the mixtures increase at first and then decrease, and the highest laminar burning velocity was measured at an equivalence ratio of 1.2. Meanwhile, with the increase of hydrogen addition, laminar burning velocities of $\mathrm{H}_{2} / \mathrm{RP}-3$ /air mixtures increase. However, the Markstein numbers of $\mathrm{H}_{2} / \mathrm{RP}-3$ / air mixtures decrease with the increase of hydrogen addition, which means that the flames of $\mathrm{H}_{2} / \mathrm{RP}-3$ /air mixtures become unstable with the increase of hydrogen addition.
\end{abstract}

Keywords: RP-3 kerosene; hydrogen addition; constant volume chamber; laminar burning velocity; Markstein number

\section{Introduction}

In order to reduce $\mathrm{NO}_{x}, \mathrm{CO}$ emissions and save fossil energy, several technologies including injection, chemical, and fuel technologies have been developed in the aircraft industry. Injection technologies try to improve fuel's atomization efficiency [1]. However, as injection technologies are always used in near stoichiometry conditions, they result in less $\mathrm{NO}_{x}$ but increased $\mathrm{CO}$ and unburned hydrocarbon emissions. Chemical strategies are also used to reduce $\mathrm{NO}_{x}$ at lean conditions. Nevertheless, $\mathrm{CO}$ emissions become quite difficult to control under lean conditions. Furthermore, it has been found that a strong correlation exists between $\mathrm{NO}_{x}$ and $\mathrm{CO}$ emissions: $\mathrm{NO}_{x}$ emissions reduction will increase $\mathrm{CO}$ emissions [2]. This trade-off problem between $\mathrm{NO}_{x}$ and $\mathrm{CO}$ emissions can only be solved by adding new degrees of freedom (e.g., hydrogen) to the system.

Fuel strategies are used to reduce $\mathrm{CO}_{2}$ emissions dramatically by replacing fossil fuel with fuel that contain no carbon [3-5]. Hydrogen is an example of such fuels being considered. However, the idea that an aircraft could be completely propelled by hydrogen is unrealistic at present or even for several decades to come, because of technical difficulties that would entail. So currently, adding hydrogen to kerosene fuel is regarded as a promising method. Frenillot et al. [6] and Hui et al. [7] found that hydrogen used as an addition fuel to kerosene can reduce pollutant emissions, improve the 
re-ignition efficiency of an aircraft in high altitude, extend the extinction and flammability limits, and enhance the combustion efficiency.

Laminar burning velocity, representing the reactivity, diffusivity, and exothermicity of a flammable mixture, is one of the combustion characteristics of Hydrogen $\left(\mathrm{H}_{2}\right) /$ kerosene mixture which can quantify the effects of hydrogen addition on kerosene/air premixed flames. Accurate measurement of laminar burning velocity is important for aircraft engine design, combustion chamber modeling, and chemical kinetics validation. Until now, many experimental and numerical investigations have shown that the laminar burning velocity of hydrogen-enriched mixtures increases with the increase of hydrogen addition in the blends [8-13]. Yu et al. [8] found that the laminar burning velocity varies linearly with the increase of hydrogen addition to a $\mathrm{CH}_{4} /$ air mixture. Zhang et al. [9] investigated the effects of hydrogen addition on the laminar burning velocity, adiabatic flame temperature, Markstein and Damkholer numbers of $\mathrm{H}_{2} / \mathrm{CH}_{4}$ /air premixed flames, and found that the Damkholer number increases with the increase of hydrogen addition, which indicated that the hydrogen addition can extend the extinction limits of the $\mathrm{CH}_{4}$ /air flame. Halter et al. [10] investigated the combustion characteristics of $\mathrm{H}_{2} / \mathrm{CH}_{4}$ /air mixtures and found that hydrogen addition can effectively increase the laminar burning velocity of $\mathrm{CH}_{4} /$ air mixtures. Law et al. [11] obtained the flame propagation photos of $\mathrm{H}_{2} / \mathrm{CH}_{4} /$ air premixed flames (with $\mathrm{CH}_{4}$ being less than $15 \%$ in volume) and concluded that the hydrogen addition increases the instability of $\mathrm{H}_{2} / \mathrm{CH}_{4} /$ air premixed flame. Tang et al. [12] experimentally studied the flame propagation speeds of outwardly spherical propagating flames of n-butane/air mixtures with hydrogen addition, and found that the laminar burning velocity increases almost linearly with the increase of hydrogen addition. Hui et al. [7] computationally studied the effects of hydrogen addition on the combustion characteristics of $n$-decane/air mixtures. They found that a small amount of hydrogen addition can significantly shorten ignition delay times at high temperatures, increase laminar burning velocities, and reduce extinction residence times of the mixtures.

To the best of our knowledge, only a few experiments or numerical simulations have been performed to study the effects of hydrogen addition on the combustion characteristics of kerosene/air premixed flames. In this paper, experiments will be carried out in a constant volume chamber and the outwardly spherical propagating flames will be used to measure the laminar burning velocities of $\mathrm{H}_{2}$ /RP-3 premixed flame. Moreover, the influences of temperature, pressure, equivalence ratio, and hydrogen addition on the laminar burning velocities and Markstein numbers of $\mathrm{H}_{2} / \mathrm{RP}-3$ / air mixtures will be studied.

\section{Experimental Facility}

Figure 1 shows the schematic diagram of the experimental facility [14]. The facilities include a combustion vessel, gas injection system, liquid fuel injection system, heating circuit system, ignition system, high-speed digital camera, and data acquisition system. Figure 2 shows the schematic diagram of the combustion vessel, which is also called the constant volume chamber. As shown in Figure 2, the combustion vessel is cylindrical and the inner diameter of the vessel is $180 \mathrm{~mm}$. The two sides of the vessel are installed with quartz glasses as observing windows, and the diameter of the visual field is $130 \mathrm{~mm}$. The gas fuel injection system consists of several valves connected to the $\mathrm{H}_{2}, \mathrm{O}_{2}$, and $\mathrm{N}_{2}$ tanks, and the liquid fuel injection system consists of a liquid fuel injection valve which is used to inject RP-3. A vacuum pump is used to evacuate the vessel after combustion and before the preparation of the mixtures. Before the experiment, the initial temperature is read by a sheathed thermocouple and the initial pressure is read through a pressure transmitter. 


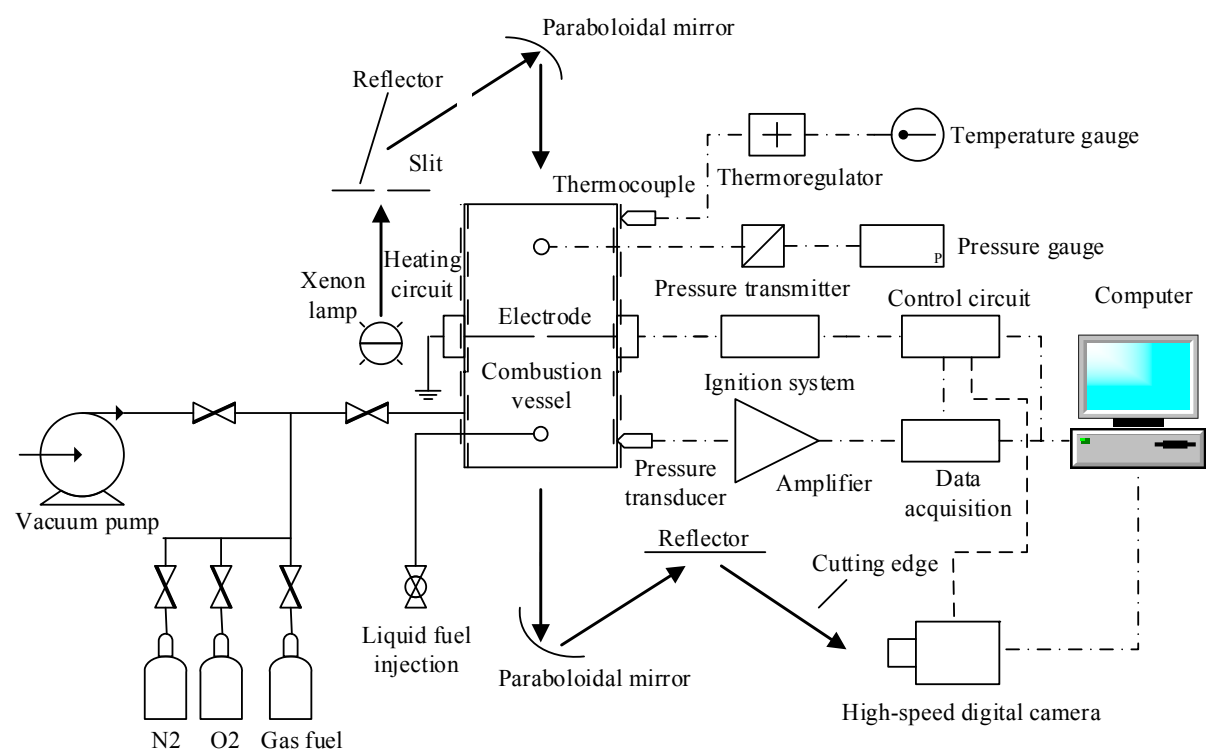

Figure 1. Schematic diagram of the experimental facility.
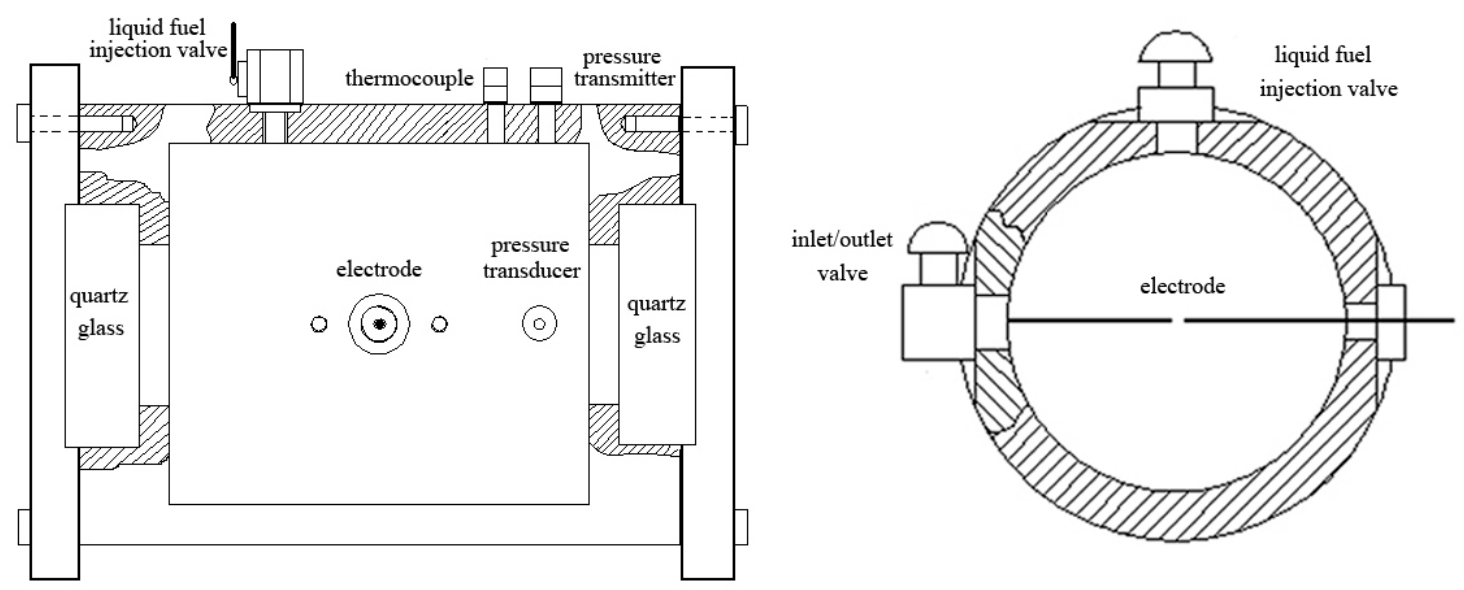

Figure 2. Schematic diagram of the constant volume combustion chamber.

The ignition system is used to ignite the premixed mixtures by the electrodes located at the center of the vessel, and the ignition system also offers a trigger signal for the high-speed digital camera. The ignition pulse width can be adjusted, helping to discard the range of flame propagation affected by the ignition. A high speed digital camera (Phantom V611,) with a frequency of 10,000 pictures per second is used to take photos through the photography method. The data collection system is installed in a computer and connected to the camera, which is used to record the snapshots of the combustion process of $\mathrm{H}_{2} / \mathrm{RP}-3$ premixed fuel. To make sure that the mixture is sufficiently uniform in the vessel before ignition (RP-3 kerosene is vaporized immediately when it is injected into the combustion vessel and remains in a gas state at the prepared initial temperature and pressure), 10 minutes was required after the vessel is filled with fuel/air mixture, and to make sure that the experiment results are more accurate, each experiment condition was examined three times and the average value is used as the experiment data.

\section{Theoretical Model}

The laminar burning velocity and Markstein number used in this paper was obtained with the spherically expanding flames. 
The stretched flame speed $S_{n}$ reflects the outwardly propagating speed of the spherical flame. It can be calculated from the spherical flame radius $r$ and elapsing time $t$, according to the method of Bradley et al. [15]:

$$
S_{n}=\frac{\mathrm{d} r}{\mathrm{~d} t}
$$

where $\mathrm{d} r$ is the increase of the flame radius between two frames and $\mathrm{d} t$ is the time interval between them.

Flame stretch rate $\alpha$ is usually defined as the changing rate of the logarithm of an infinite area element on the flame front:

$$
\alpha=\mathrm{d}(\ln A) / \mathrm{d} t=\mathrm{d} A /(A \mathrm{~d} t)
$$

where $A$ is the area of flame surface.

For a spherical flame, the flame stretch rate $\alpha$ can be given as:

$$
\alpha=2 \mathrm{~d} r /(r \mathrm{~d} t)=2 S_{n} / r
$$

To obtain an accurate laminar burning velocity, the proper extrapolation methods need to be selected. Previous studies $[16,17]$ have shown that the uncertainties of extrapolation depend on the Lewis number. The relationship between stretched flame speed and flame stretch rate is linear only when Lewis number is unit. For $\mathrm{H}_{2} / \mathrm{RP}-3$ premixed flame, the Lewis number is larger than the unit at all conditions. According to Chen [17], there is a non-linear relationship between the unstretched laminar flame speed $S_{1}$ and the stretched flame speed $S_{n}$; this relationship is described as:

$$
S_{n}=S_{1}-S_{1} L_{\mathrm{b}} \frac{2}{r} \text { or } S_{n}=S_{1}-\frac{S_{1} L_{\mathrm{b}}}{S_{n}} \alpha
$$

where $L_{\mathrm{b}}$ is the Markstein number.

An equation between laminar burning velocity $U_{1}$ and the unstretched flame speed $S_{1}$ is given as:

$$
A \rho_{\mathrm{u}} U_{1}=A \rho_{\mathrm{b}} S_{1}
$$

where $\rho_{\mathrm{u}}$ and $\rho_{\mathrm{b}}$ are densities of the unburnt and burnt mixtures; $\rho_{\mathrm{u}}$ is determined by the initial state of the mixture; and $\rho_{\mathrm{b}}$ can be calculated by the chemical equilibrium. By Equation (5), the laminar burning velocity $U_{1}$ is obtained as:

$$
U_{1}=\left(\rho_{\mathrm{b}} S_{1}\right) / \rho_{\mathrm{u}}
$$

The method of Moffat [18] is used to estimate the uncertainty of the laminar burning velocity in this study. The relationship between the laminar burning velocity and various factors such as the equivalence ratio, initial pressure, and initial temperature, can be obtained through the equation as follows:

$$
U_{1}=U_{1}(\phi)\left(T / T_{0}\right)^{\alpha_{\mathrm{T}}(\phi)}\left(P / P_{0}\right)^{\beta_{\mathrm{T}}(\phi)}
$$

where the referenced initial temperature $T_{0}$ is $398 \mathrm{~K}$ and the referenced initial pressure $P_{0}$ is $0.1 \mathrm{MPa}$. Since the accuracy of the thermocouple is $\pm 3 \mathrm{~K}$ and the initial experimental temperatures are 390 and $420 \mathrm{~K}$, the biggest relative error of temperature is under $\pm 1 \%$. Because the deviation between the target and the actual pressure is $\pm 1 \mathrm{kPa}$, the relative error of pressure is within $\pm 1 \%$. The liquid fuels are directly injected into the combustion chamber by microliter syringes, and the amount is presented by practical pressure measured by the pressure gauge. The relative uncertainty of equivalence ratio is mainly induced by the uncertainties in measuring the partial pressures of RP-3, $\mathrm{H}_{2}, \mathrm{O}_{2}$, and $\mathrm{N}_{2}$. Because the precision of the pressure transmitter used in this study is $0.075 \%$ in the measuring range, the uncertainties of the equivalence ratio are estimated to be within the range of $1-3 \%$. According to the analyses above, the total uncertainty of the laminar burning velocity is evaluated to be $1-4.5 \mathrm{~cm} / \mathrm{s}$ in this study. 
Chinese RP-3 kerosene is widely used in China. It consists of 92.1\% (in Volume) saturated hydrocarbons and $7.9 \%$ aromatic hydrocarbons. The detail compositions are listed in Table 1 and the composition of this kerosene was discussed in detailed by Ma et al. [19]. In our previous studies [20], a surrogate fuel which consists of $65 \%$ (in Vol.) $n$-decane, $10 \%$ toluene, and $25 \%$ propylcyclohexane was selected for RP-3 kerosene. The calculated ignition delay time of the surrogate fuel was found to agree well with the experimental data of RP-3. In this study, the formula of RP-3 kerosene can be calculated as $\mathrm{C}_{9.45} \mathrm{H}_{19.6}$.

Table 1. Compositions of Chinese No.3 jet fuel (RP-3 kerosene).

\begin{tabular}{lcc}
\hline \multicolumn{2}{c}{ Composition } & Vol. \% \\
\hline \multirow{3}{*}{ Saturated hydrocarbons } & Alkanes & 52.2 \\
& Monocyclic naphthenes & 33.8 \\
& Bicyclic naphthenes & 6.0 \\
& Tricyclic naphthenes & 0.1 \\
\hline \multirow{3}{*}{ Aromatic hydrocarbons } & Alkyl benzenes & 5.1 \\
& Indan tetralin & 1.3 \\
& Naphthalene & 0.6 \\
& Naphthalene derivatives & 0.9 \\
\hline
\end{tabular}

The hydrogen addition ratio of the $\mathrm{H}_{2} / \mathrm{RP}-3$ mixture is defined as:

$$
R_{\mathrm{H}_{2}}=\frac{V_{\mathrm{H}_{2}}}{V_{\mathrm{RP}-3}+V_{\mathrm{H}_{2}}}
$$

where $V_{\mathrm{H}_{2}}$ and $V_{\mathrm{RP}-3}$ are the respective volume fractions of hydrogen and RP-3 kerosene in the blends.

The equivalence ratio $\phi$ is defined as:

$$
\phi=\frac{\mathrm{F} / \mathrm{A}}{(\mathrm{F} / \mathrm{A})_{\mathrm{st}}}
$$

where $\mathrm{F} / \mathrm{A}$ refers to the fuel-air ratio and $(\mathrm{F} / \mathrm{A})_{\text {st }}$ refers to the stoichiometric value of $\mathrm{F} / \mathrm{A}$.

The $\mathrm{H}_{2} / \mathrm{RP}-3$ /air mixture can be expressed by the following:

$$
\left(1-R_{\mathrm{H}_{2}}\right) \mathrm{C}_{9.45} \mathrm{H}_{19.6}+R_{\mathrm{H}_{2}} \times \mathrm{H}_{2}+\left(\frac{14.35}{\phi}\left(1-R_{\mathrm{H}_{2}}\right)+\frac{R_{\mathrm{H}_{2}}}{2 \phi}\right)\left(\mathrm{O}_{2}+3.762 \mathrm{~N}_{2}\right)
$$

\section{Experimental Results and Discussion}

The experimental facility and measurement technique used in this work have been already validated by $\mathrm{Hu}$ et al. [14]. In this work, experiments will be carried out for $\mathrm{H}_{2} / \mathrm{RP}-3$ / air mixtures at initial temperatures of 390 and $420 \mathrm{~K}$, initial pressures of 0.1 and $0.3 \mathrm{MPa}$, equivalence ratios of 0.6-1.6, and hydrogen additions of 0.0 to 0.5 , and the effects of hydrogen addition on the laminar burning velocities and Markstein numbers of $\mathrm{H}_{2} / \mathrm{RP}-3$ / air mixtures will be discussed.

\subsection{Effects of Hydrogen Addition on Flame Propagation Characteristics}

Ignition energy affects the value of the laminar burning velocity [21-23]. So, when the outwardly spherical propagating flame is used to measure the laminar burning velocity, the range of flame radius should be selected to avoid the influence of ignition energy. Bradley et al. [21] and Huang et al. [22] indicated that the laminar burning velocity was independent with ignition energy when the flame radius was larger than $6 \mathrm{~mm}$.

In addition, the increased pressure in the constant volume chamber also affects the value of laminar burning velocity. Burke et al. [23] found that the pressure hardly changed when the flame radius was less than $25 \mathrm{~mm}$. In order to eliminate the influences of ignition energy and the increased 
pressure, photos of the outwardly spherical propagating flame used in our study were selected in the radius range of $6-25 \mathrm{~mm}$. In addition, the flame photos with cellular structures were neglected during the data processing.

Figure 3 shows the snapshots of $\mathrm{H}_{2} / \mathrm{RP}-3$ /air premixed flames at a selected condition with the initial temperature of $390 \mathrm{~K}$, initial pressure of $0.3 \mathrm{MPa}$, equivalence ratio of 1.3 , and hydrogen additions over the range from 0 to 0.5 .

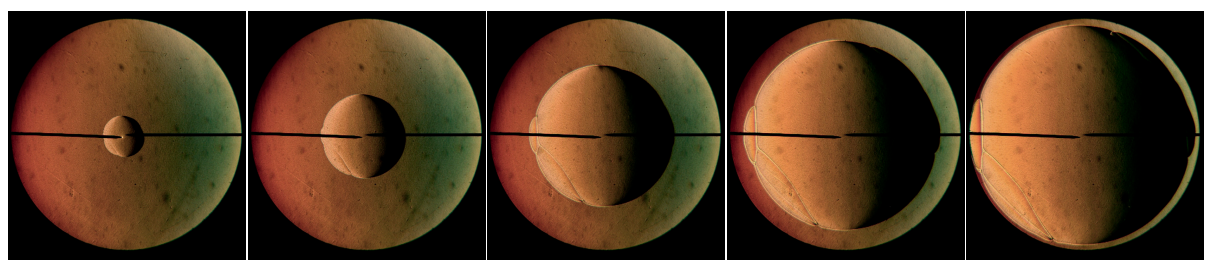

(a)

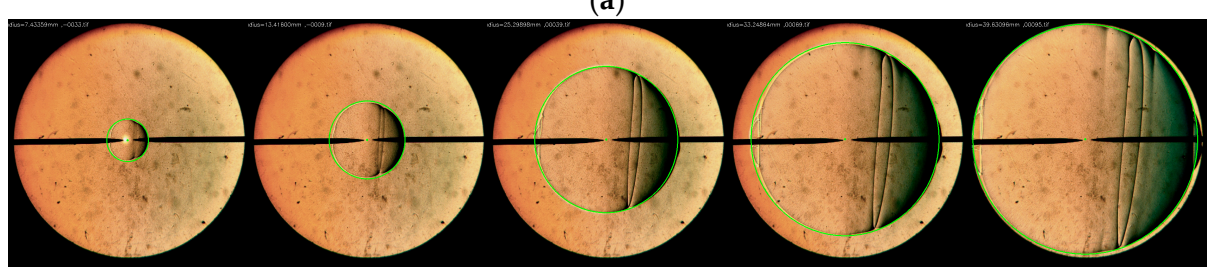

(b)

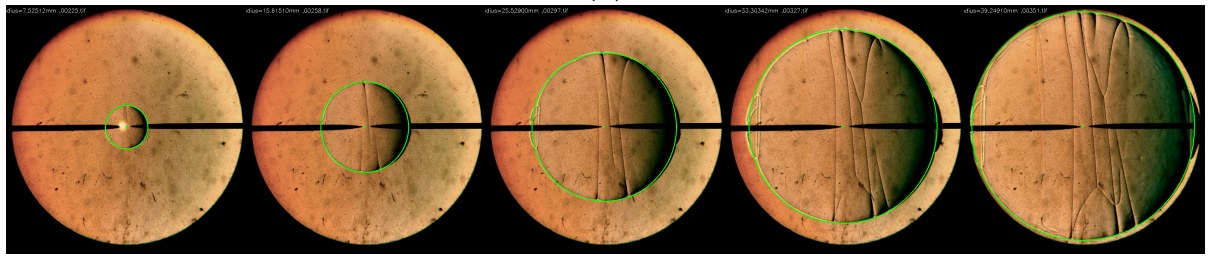

(c)

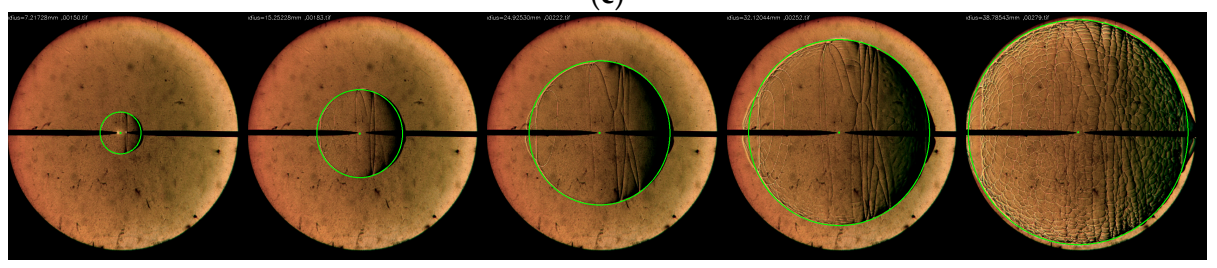

(d)

Figure 3. Effect of hydrogen addition on flame propagation characteristics. (a) $R_{\mathrm{H}_{2}}=0.0$; (b) $R_{\mathrm{H}_{2}}=0.1$; (c) $R_{\mathrm{H}_{2}}=0.3 ;$ (d) $R_{\mathrm{H}_{2}}=0.5$.

Figure 3 shows the propagation of the $\mathrm{H}_{2} / \mathrm{RP}-3$ premixed flame from the center of the chamber where the electrodes locate to the outward. As shown in Figure 3a, when the hydrogen addition is 0.0, at the early stage of flame development, the cooling effect of electrodes is observed and this effect leads to a slower flame propagation speed in the electrodes direction than that in the vertical direction. However, when the flame radius propagates to a certain value, the cooling effect becomes trivial. So, in order to avoid the influence of electrodes, the flame radius in the vertical direction is used.

As shown in Figure $3 b$, slight flaws and protuberances can be observed at the early stage of flame development and then develop further with flame propagation when the hydrogen addition is 0.1 . Furthermore, when the hydrogen addition increases to 0.5, as shown in Figure 3d, large flaws and protuberances are observed at the beginning of flame propagation, which result in a cellular surface structure later. Figure $3 a-d$ indicates that the $\mathrm{H}_{2} / \mathrm{RP}-3$ premixed flame tends to be unstable with the increase of hydrogen addition under some conditions.

Figure 4 shows the flame radius versus time at an initial pressure of $0.1 \mathrm{MPa}$, initial temperatures of 390 and $420 \mathrm{~K}$, equivalence ratios of $0.9,1.2,1.5$, and hydrogen additions of $0.0,0.3,0.5$. As shown in 
Figure 4, a near-linear relationship between the flame radius and time is observed, and the slope of the line increases with the increase of hydrogen addition. The result indicates that the flame propagating speed increases with the increase of hydrogen addition.

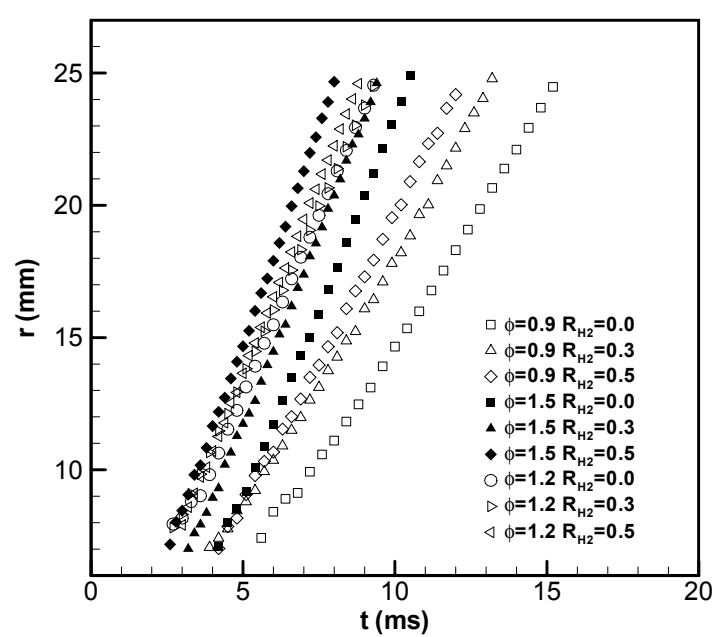

(a)

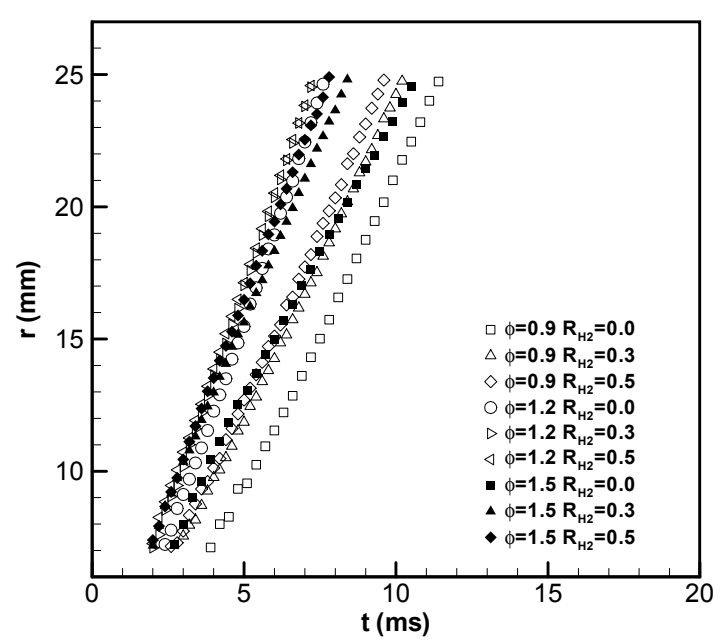

(b)

Figure 4. Effect of hydrogen addition on flame radius versus time. (a) $T=390 \mathrm{~K}$; (b) $T=420 \mathrm{~K}$.

In order to explain the characteristic of the flame propagation in detail, the stretched flame speed as a function of the flame radius is obtained. The stretched flame speeds versus the flame radius at the initial temperatures of 390 and $420 \mathrm{~K}$, initial pressure of $0.1 \mathrm{MPa}$, equivalence ratios of $0.9,1.2,1.5$, and hydrogen additions of 0.0, 0.3, 0.5 are shown in Figure 5.

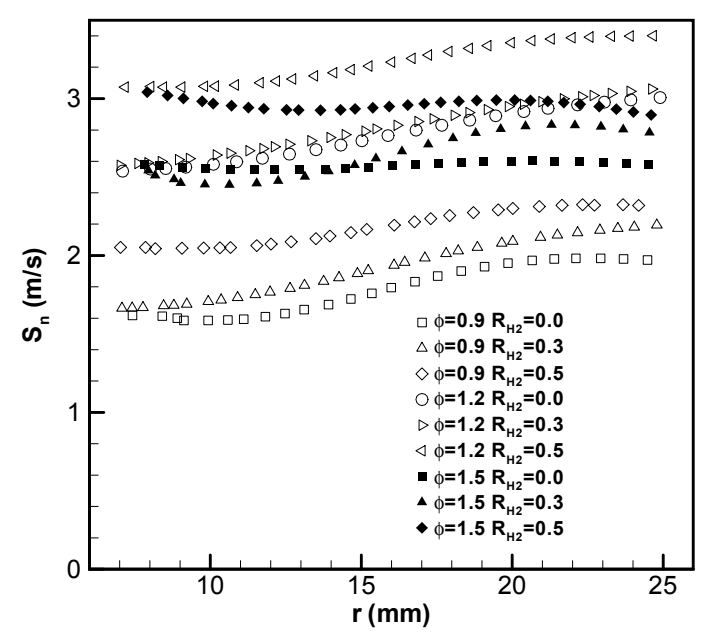

(a)

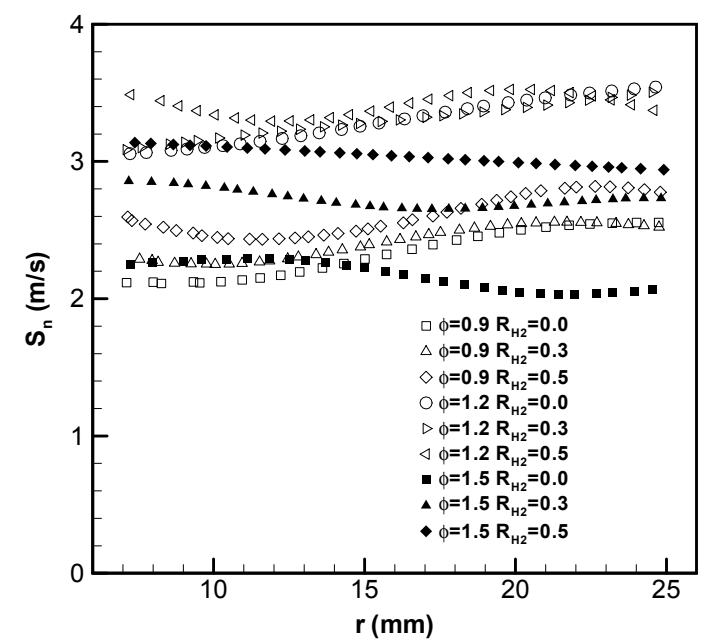

(b)

Figure 5. Effect of hydrogen addition on $S_{n}$ versus flame radius. (a) $T=390 \mathrm{~K}$; (b) $T=420 \mathrm{~K}$.

The stretched flame speed reveals the flame propagating speed relative to the motionless chamber wall, and stretched flame speed shows different trends with different initial temperatures, pressures, equivalence ratios, and hydrogen additions. It can be observed in Figure 5 that for both initial temperatures of 390 and $420 \mathrm{~K}$, the stretched flame speeds of $\mathrm{H}_{2} / \mathrm{RP}-3$ mixtures decrease at the beginning of flame propagation and subsequently increase with the equivalence ratios of 0.9 and 1.5. However, the stretched flame speeds increase with the equivalence ratio of 1.2 from the early stage of the flame propagation to the end. 
In Figure 5, it can also be observed that the stretched flame speed also increases with the increased hydrogen addition under all conditions.

The stretched flame speed can be plotted as a function of stretch rate to explain the effect of stretch on the flame propagation. Figure 6 shows the stretched flame speed versus stretch rate under some selected conditions, with initial temperatures of 390 and $420 \mathrm{~K}$, initial pressure of $0.1 \mathrm{MPa}$, equivalence ratios of 0.9 and 1.2 , and hydrogen additions of $0.0,0.3,0.5$.

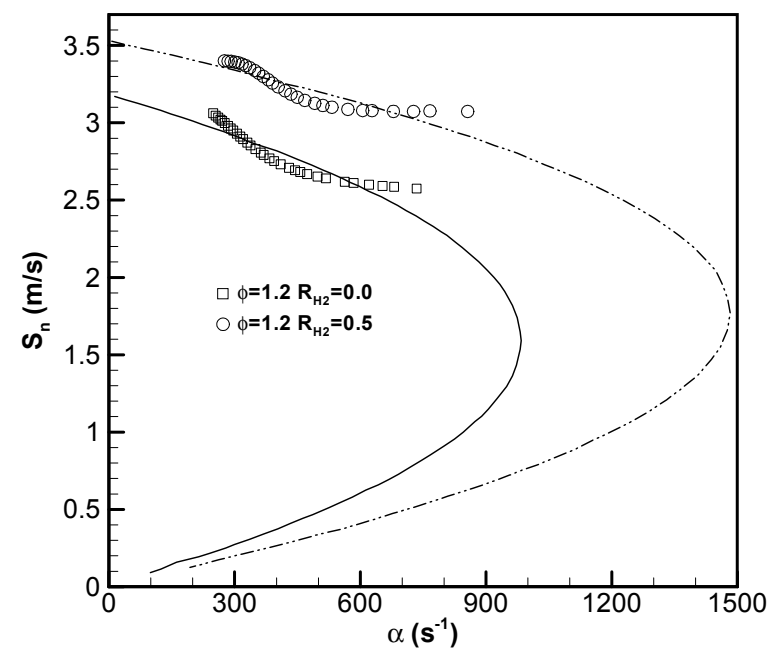

(a)

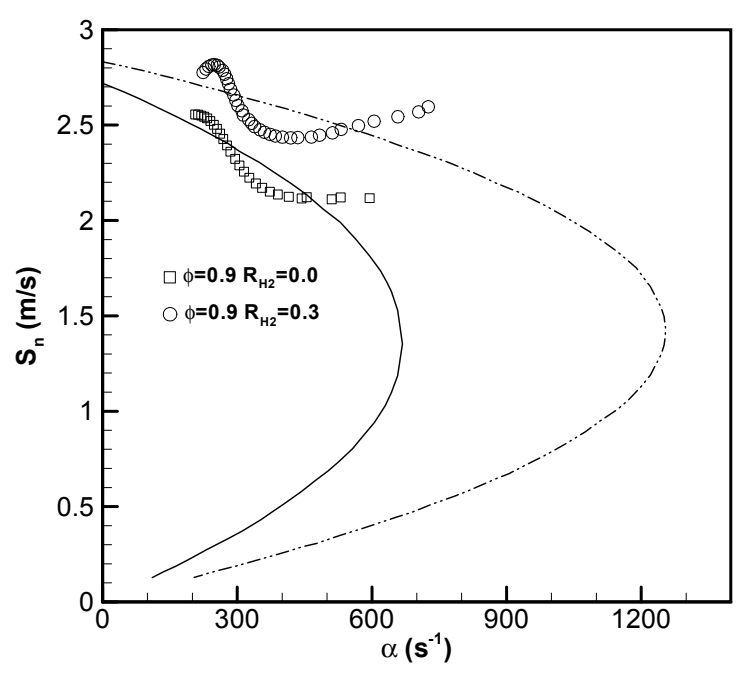

(b)

Figure 6. Effect of hydrogen addition on $S_{n}$ versus flame stretch. (a) $T=390 \mathrm{~K}$; (b) $T=420 \mathrm{~K}$.

The laminar burning velocity is generally defined for one-dimensional planar flame, and there is no effect of stretch on this kind of flame. According to Chen [17], the unstretched flame speed can be obtained using Equation (4). In Figure 6, the nonlinear method is used to extract the unstretched flame speed $S_{1}$, which can be obtained by a zero stretch extrapolation, and the lines are obtained by fitting experimental data.

As shown in Figure 6, the unstretched flame speeds increase and burned gas Markstein numbers decrease (as shown in Figure 7) with the hydrogen addition at the equivalence ratios of 1.2 and 0.9. The decrease of Markstein number indicates that the stability of the $\mathrm{H}_{2} / \mathrm{RP}-3$ premixed flame decreases, which will be discussed in detail in the next section.

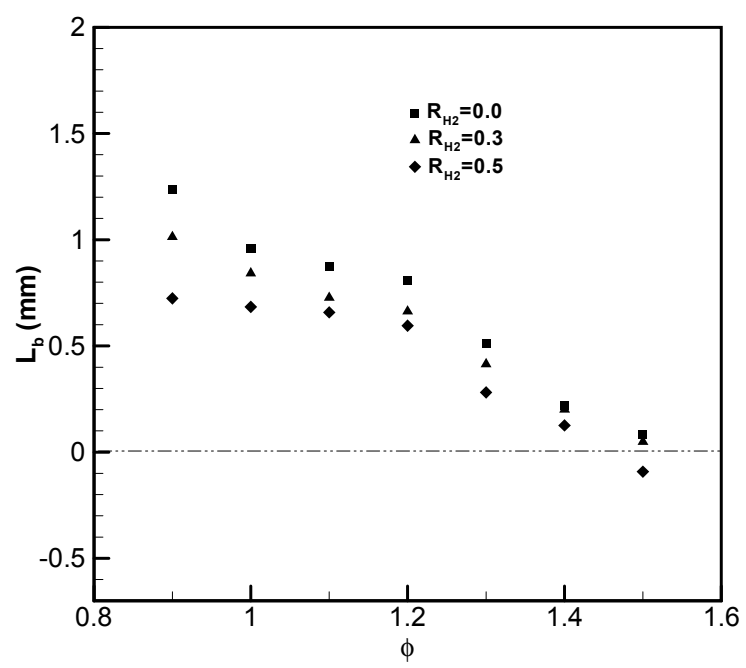

Figure 7. Effect of hydrogen addition on the Markstein number versus equivalence ratio. 


\subsection{Effect of Hydrogen Addition on Flame Stability}

Several disturbed sources, such as spark, interaction with electrodes, density gradient, and stoichiometry gradient in the mixture, can cause flame instability. Ma et al. [19] indicated that the Markstein number $\left(L_{\mathrm{b}}\right)$ is an important parameter to reflect the flame instability. A stable flame tends to restrain these disturbed effects on the flame front, which indicates that the stretched flame speed decreases with the increase of stretch rate, and the Markstein number value is positive. Moreover, the highly positive Markstein number value indicates that the flame is considerably stable. On the other hand, a negative Markstein number value means that the stretched flame speed increases with the increase of stretch rate, and the Markstein number value is negative. Any kind of disturbed source can likewise affect the flame front and thus cause flame front instability.

Figure 7 shows the Markstein numbers of $\mathrm{H}_{2}$ / RP-3/air premixed flames versus the equivalence ratio at an initial temperature of $390 \mathrm{~K}$, initial pressure of $0.1 \mathrm{MPa}$, and hydrogen additions of $0.0,0.3$, 0.5. As shown in Figure 7, the Markstein number decreases with the increase of the equivalence ratio under all hydrogen addition conditions. In addition, the Markstein number tends to decline with the increase of hydrogen addition, which reveals that the flame stability decreases with the increase of hydrogen addition. This phenomenon can be explained with the classical models because of the effects of preferential diffusion proposed by Manton et al. [24]. The laminar premixed flames tend to be unstable due to the effects of preferential diffusion under the conditions where the fast-diffusing component is deficient. Hu et al. [14], Tang et al. [12], and Hui et al. [7] also reported the same results concerning the effects of hydrogen addition on the Markstein numbers of methane, n-butane, and $n$-decane.

\subsection{Effect of Hydrogen Addition on Laminar Burning Velocity}

Figure 8 shows the unstretched flame speed $S_{1}$ and the laminar burning velocity $U_{1}$ versus the equivalence ratio at initial temperatures of 390 and $420 \mathrm{~K}$, initial pressure of $0.1 \mathrm{MPa}$, and hydrogen additions of $0.0-0.5$.

As shown in Figure 8, with the increase of the equivalence ratio from 0.9 to 1.5, the unstretched flame speed and the laminar burning velocity increase at first and then decrease. The highest unstretched flame speed and laminar burning velocity are observed at the equivalence ratio of 1.2. Moreover, with the initial temperature increasing from $390 \mathrm{~K}$ to $420 \mathrm{~K}$, the unstretched flame speed and the laminar burning velocity are increased under any of the same conditions. Furthermore, the unstretched flame speed and the laminar burning velocity increase with the increase of hydrogen addition at all conditions. The result shows that the hydrogen addition has the effect to increase the laminar burning velocity. Tang et al. [12] and Hui et al. [7] also reported the same results concerning the effects of hydrogen addition on the laminar burning velocities of $n$-butane and $n$-decane.

The effect of hydrogen addition on the laminar burning velocity is a consequence of the combined effects of thermal conduction, chemical reaction, and diffusion. Considering that the hydrogen addition range is relatively small and the laminar burning velocity only scales with the square root of the Lewis number, it is reasonable to expect that the diffusion effect due to hydrogen addition will be minor compared to the thermal and chemical effects, and thus can be neglected. Hydrogen has higher adiabatic flame temperatures than RP-3; thus, the addition of hydrogen will obviously increase the adiabatic flame temperatures of the RP-3/air mixtures, leading to a corresponding increase in the laminar burning velocity. Furthermore, hydrogen addition will generate more $\mathrm{H}$ and $\mathrm{OH}$ radicals. A strong correlation exists between the laminar burning velocity and the maximum radical concentrations of $\mathrm{H}$ and $\mathrm{OH}$ radicals in the reaction zone of premixed flames. It is expected that the increase in the maximum concentration of $\mathrm{H}$ and $\mathrm{OH}$ will lead to the corresponding increase of the laminar burning velocity of flames. 


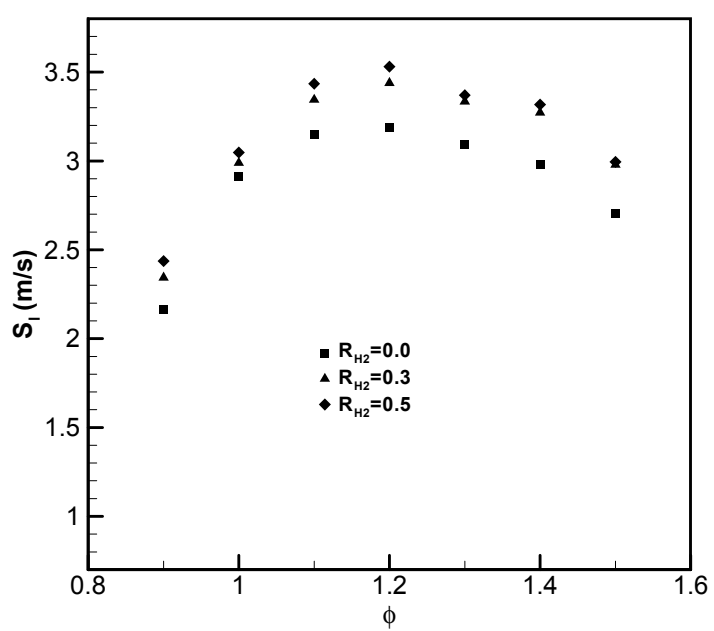

(a)

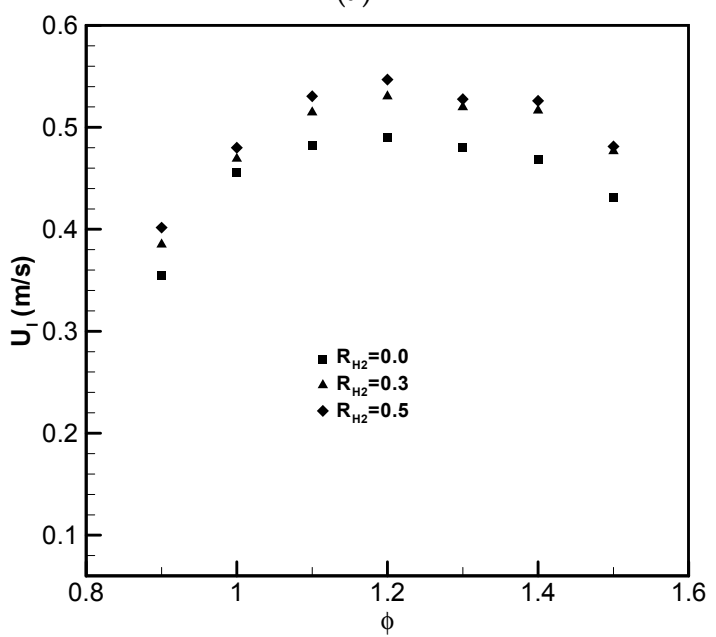

(c)

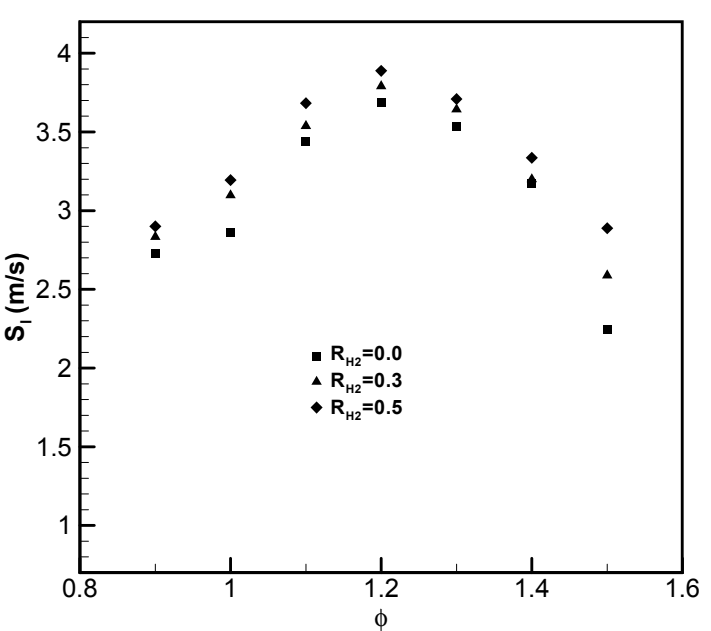

(b)

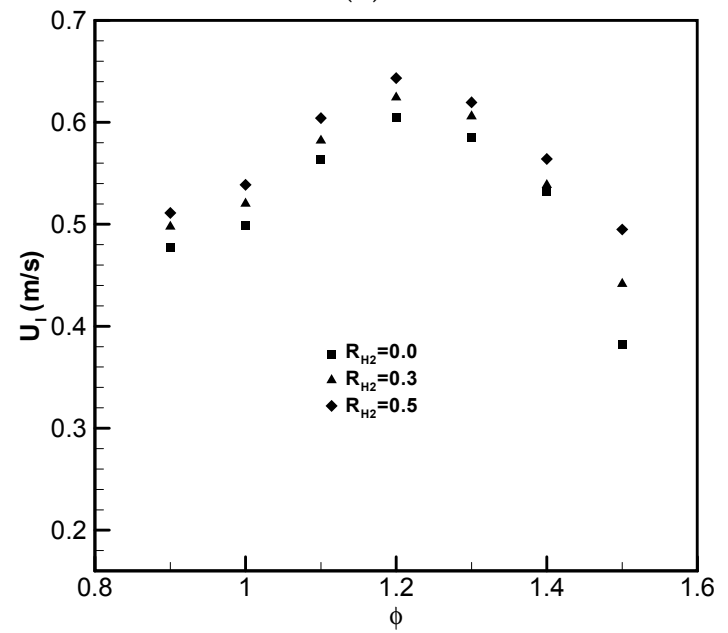

(d)

Figure 8. Effect of hydrogen addition on $S_{1}$ and $U_{1}$ versus equivalence ratio. (a) $T=390 \mathrm{~K}$; (b) $T=$ $420 \mathrm{~K}$; (c) $T=390 \mathrm{~K}$; (d) $T=420 \mathrm{~K}$.

\section{Conclusions}

In our study, the effects of hydrogen addition on the laminar burning velocities and Markstein numbers of RP-3/air mixtures were investigated in a constant volume chamber. The main results are summarized as follows:

(1) The flame front surfaces of RP-3/air mixtures remain smooth throughout the entire flame propagation process at the initial temperature of $390 \mathrm{~K}$, initial pressure of $0.3 \mathrm{MPa}$, and without hydrogen addition. When the hydrogen addition increases from 0.1 to 0.5 , flaws and protuberances occur at the flame front surface. This result indicates that the $\mathrm{H}_{2} / \mathrm{RP}-3$ premixed flame tends to be unstable with the increase of hydrogen addition.

(2) A near-linear relationship between the flame radius and time can be observed. The slope of the line increases with the increase of hydrogen addition. This result indicates that the flame propagating speed increases with the increase of hydrogen addition.

(3) The Markstein number decreases with the increase of equivalence ratio under all conditions. It also tends to decline with the increase of hydrogen addition, which reveals that the flame stability decreases with the increase of hydrogen addition. 
(4) The unstretched flame speed and the laminar burning velocity increase with the increase of hydrogen addition under all conditions, which shows that the hydrogen addition induces an increase in the laminar burning velocity.

Acknowledgments: The authors appreciate the financial supports from the National Natural Science Foundation of China $(51376133,51676132,51606129)$.

Author Contributions: Baodong Chen conceived and designed the experiments; Wen Zeng, Yu Liu and Aiguo Liu performed the experiments; Jing Liu analyzed the data; Wen Zeng wrote the paper.

Conflicts of Interest: The authors declare no conflict of interest.

\section{References}

1. Burguburu, J.; Cabot, G.; Renou, B.; Boukhalfa, A.M.; Cazalens, M. Effects of $\mathrm{H}_{2}$ enrichment on flame stability and pollutant emissions for a kerosene/air swirled flame with an aeronautical fuel injector. Proc. Combust. Inst. 2011, 33, 2927-2935. [CrossRef]

2. Frolov, S.M.; Medvedev, S.N.; Basevich, V.Y.; Frolov, F.S. Self-ignition of hydrocarbon-hydrogen-air mixtures. Int. J. Hydrog. Energy 2013, 38, 4177-4184. [CrossRef]

3. Cazalens, M.; Roux, S.; Sensiau, C.; Poinsot, T. Combustion instability problem analysis for high-pressure jet engine cores. J. Propuls. Power 2008, 24, 770-778. [CrossRef]

4. Hagling, F.; Singh, R. Design of aero gas turbine using hydrogen. J. Eng. Gas Turbines Power 2006, 128, 754-768. [CrossRef]

5. Dahl, G.; Suttrop, F. Engine control and low $\mathrm{NO}_{\mathrm{x}}$ combustion for hydrogen fuelled aircraft gas turbines. Int. J. Hydrog. Energy 1998, 23, 695-704. [CrossRef]

6. Frenillot, J.P.; Cabot, G.; Cazalens, M.; Renou, B.; Boukhalfa, M.A. Impact of $\mathrm{H}_{2}$ addition on flame stability and pollutant emissions for an atmospheric kerosene/air swirled flame of laboratory scaled gas turbine. Int. J. Hydrog. Energy 2009, 34, 3930-3944. [CrossRef]

7. Hui, X.; Zhang, C.; Xia, M.; Sung, C.J. Effects of hydrogen addition on combustion characteristics of n-decane/air mixtures. Combust. Flame 2014, 161, 2252-2262. [CrossRef]

8. Yu, G.; Law, C.K.; Wu, C.K. Laminar flame speeds of hydrocarbon/air mixtures with hydrogen addition. Combust. Flame 1986, 63, 339-347. [CrossRef]

9. Zhang, Y.; Wu, J.; Ishizuka, S. Hydrogen addition effect on laminar burning velocity, flame temperature and flame stability of a planar and a curved $\mathrm{CH}_{4} / \mathrm{H}_{2}$ /air premixed flame. Int. J. Hydrog. Energy 2009, 34, 519-527. [CrossRef]

10. Halter, F.; Chauveau, C.; Djebayli, C.N. Characterization of effects of pressure and hydrogen concentration on laminar burning velocities of methane/hydrogen/air mixture. Proc. Combust. Inst. 2005, 30, 201-208. [CrossRef]

11. Law, C.; Kwon, O. Effects of hydrocarbon substitution on atmospheric hydrogen/air flame propagation. Int. J. Hydrog. Energy 2004, 29, 867-879. [CrossRef]

12. Tang, C.L.; Huang, Z.H.; Law, C.K. Determination, correlation, and mechanistic interpretation of effects of hydrogen addition on laminar flame speeds of hydrocarbon/air mixtures. Proc. Combust. Inst. 2011, 33, 921-928. [CrossRef]

13. Weiss, M.; Zarzalis, N.; Suntz, R. Experimental study of Markstein number effects on laminar flamelet velocity in turbulent premixed flames. Combust. Flame 2008, 154, 671-691. [CrossRef]

14. Hu, E.J.; Huang, Z.H.; He, J.J.; Jin, C.; Zheng, J.J. Experimental and numerical study on laminar burning characteristics of premixed methane/hydrogen/air flames. Int. J. Hydrog. Energy 2009, 34, 4876-4888. [CrossRef]

15. Bradley, D.; Hicks, R.A.; Lawes, M.; Sheppard, C.G.W.; Woolley, R. The measurement of laminar burning velocities and Markstein numbers for iso-octane/air and iso-octane/n-heptane/air mixtures at elevated temperatures and pressures in an explosion bomb. Combust. Flame 1998, 115, 126-144. [CrossRef]

16. Wu, F.; Liang, W.; Chen, Z.; Ju, Y.; Law, C.K. Uncertainty in stretch extrapolation of laminar flame speed from expanding spherical flames. Proc. Combust. Inst. 2015, 35, 663-670. [CrossRef]

17. Chen, Z. On the extraction of laminar flame speed and Markstein length from outwardly propagating spherical flames. Combust. Flame 2011, 158, 291-300. [CrossRef] 
18. Moffat, R.J. Describing the uncertainties in experimental results. Exp. Therm. Fluid Sci. 1988, 1, 3-17. [CrossRef]

19. Ma, H.A.; Xie, M.Z.; Zeng, W.; Chen, B.D. Experimental study on combustion characteristics of Chinese RP-3 kerosene. Chin. J. Aeronaut. 2016, 29, 375-385. [CrossRef]

20. Zeng, W.; Li, H.X.; Chen, B.D.; Ma, H.A. Experimental and kinetic modeling study of ignition characteristics of Chinese RP-3 kerosene. Combust. Sci. Technol. 2015, 187, 396-409. [CrossRef]

21. Bradley, D.; Gaskell, P.H.; Gu, X.J. Burning velocities, Markstein numbers, and flame quenching for spherical methane-air flames: A computational study. Combust. Flame 1996, 104, 176-198. [CrossRef]

22. Huang, Z.H.; Wang, Q.; Yu, J.R.; Zhang, Y.; Zeng, K.; Miao, H.Y. Measurement of laminar burning velocity of dimethylether/air premixed mixtures. Fuel 2007, 86, 2360-2366. [CrossRef]

23. Burke, M.P.; Chen, Z.; Ju, Y.; Dryer, F.L. Effect of cylindrical confinement on the determination of laminar flame speeds using outwardly propagating flames. Combust. Flame 2009, 156, 771-779. [CrossRef]

24. Manton, J.; Elbe, G.; Lewis, B. Burning-velocity measurements in a spherical vessel with central ignition. Proc. Combust. Inst. 1953, 4, 358-363. [CrossRef]

(C) 2017 by the authors. Licensee MDPI, Basel, Switzerland. This article is an open access article distributed under the terms and conditions of the Creative Commons Attribution (CC BY) license (http:/ / creativecommons.org/licenses/by/4.0/). 